\title{
Modulatory effects of garlic, ginger, turmeric and their mixture on hyperglycaemia, dyslipidaemia and oxidative stress in streptozotocin-nicotinamide diabetic rats
}

\author{
Hafez R. Madkor ${ }^{1}$, Sherif W. Mansour ${ }^{1}$ and Gamal Ramadan ${ }^{2,3 *}$ \\ ${ }^{1}$ Biomedical Science Department, College of Clinical Pharmacy, King Faisal University, Al-Hufof, KSA \\ ${ }^{2}$ Biological Science Department, College of Science, King Faisal University, Al-Hufof, KSA \\ ${ }^{3}$ Zoology Department, Faculty of Science, Ain Shams University, Abbasseya 11566, Cairo, Egypt \\ (Received 25 May 2010 - Revised 28 October 2010 - Accepted 29 October 2010 - First published online 10 December 2010)
}

\begin{abstract}
Spices which show hypoglycaemic, hypolipidaemic and antioxidant activities may have a role in the treatment of diabetes and its complications. The present study aimed to compare the modulatory effects of garlic, ginger, turmeric and their mixture on the metabolic syndrome and oxidative stress in streptozotocin (STZ) - nicotinamide diabetic rats. Diabetes was induced in overnight fasted rats by a single intraperitoneal injection of STZ ( $65 \mathrm{mg} / \mathrm{kg}$ body weight) and nicotinamide ( $110 \mathrm{mg} / \mathrm{kg}$ body weight, $15 \mathrm{~min}$ before STZ injection). Diabetic rats orally received either distilled water (as vehicle) or $200 \mathrm{mg} / \mathrm{kg}$ body weight of garlic bulb, ginger rhizome or turmeric rhizome powder suspension separately or mixed together (GGT mixture) for twenty-eight consecutive days. The results showed that these spices and their mixture significantly alleviated (80-97\%, $P<0.05-0 \cdot 001)$ signs of the metabolic syndrome (hyperglycaemia and dyslipidaemia), the elevation in atherogenic indices and cellular toxicity in STZ-nicotinamide diabetic rats by increasing the production of insulin (26-37\%), enhancing the antioxidant defence system (31-52\%, especially GSH) and decreasing lipid peroxidation (60-97\%). The greatest modulation was seen in diabetic rats that received garlic and the GGT mixture (10-23\% more than that in the ginger and turmeric groups). In conclusion, garlic or the mix including garlic appears to have an impact on each of the measures more effectively than ginger and turmeric and may have a role in alleviating the risks of the metabolic syndrome and cardiovascular complications.
\end{abstract}

Key words: Albino rats: Antioxidant activity: Complementary/alternative medicine: Metabolic syndrome: Streptozotocinnicotinamide diabetes

The number of individuals suffering from diabetes worldwide is predicted to reach 325 million by the year 2025 due to sedentary lifestyle, consumption of energy-rich diet, obesity, longer life span, etc. ${ }^{(1)}$. There are two forms of diabetes mellitus: type 1 and type 2 . In type 1 or insulindependent diabetes, pancreatic $\beta$-cells are progressively destroyed and secrete little or no insulin. Type 2 or noninsulin-dependent diabetes is a heterogeneous disorder of insulin resistance and pancreatic $\beta$-cell dysfunction ${ }^{(1)}$. Cardiovascular complications due to the metabolic syndrome, a clustering of pathological conditions including obesity, dyslipidaemia, hepatic steatosis and insulin resistance, are a major cause of morbidity and mortality in diabetic patients $^{(2)}$. Dyslipidaemia (lipid abnormalities) resulting from uncontrolled hyperglycaemia and insulin resistance in diabetic patients is a major risk factor for coronary artery disease, stroke and peripheral vascular disease ${ }^{(3)}$.
Streptozotocin (STZ) has been widely used for inducing type 1 diabetes in a variety of animals by causing severe degeneration of pancreatic $\beta$-cells ${ }^{(4)}$. Recently, a new rat model of type 2 diabetes that shares a number of features with human type 2 diabetes mellitus has been described ${ }^{(5)}$. In this model, the diabetic syndrome is experimentally induced in adult rats by the administration of a low dose of STZ after the pancreatic $\beta$-cells were partially protected from STZ-induced necrosis by a suitable dose of nicotinamide ${ }^{(6)}$. Therefore, this model is characterised by only $40 \%$ reduction in $\beta$-cell mass, which results in moderate and stable hyperglycaemia, glucose intolerance, altered but significant glucose-stimulated insulin secretion and in vivo as well as in vitro responsiveness to sulfonylureas $^{(6)}$. This model may provide a particularly advantageous tool for pharmacological investigations of new insulinotropic agents ${ }^{(6)}$. Recently, attention has been focused on the

Abbreviations: ALAT, alanine aminotransferase; GGT mixture, mixture of garlic, ginger and turmeric; STZ, streptozotocin; TBARS, thiobarbituric acidreactive substances.

*Corresponding author: G. Ramadan, fax +20 26842123, email gamal_ramadan@hotmail.com 
relationship between production of free radicals, especially reactive oxygen species, and the pathogenesis as well as progression of diabetes mellitus. Mechanisms that contribute to the formation of free radicals in diabetes mellitus may include metabolic stress resulting from changes in energy metabolism, inflammatory mediators and impaired antioxidant defence mechanisms ${ }^{(7)}$. STZ induces oxidative stress and depletion of antioxidant systems in both blood and tissues, causing membrane lipid peroxidation and hence cellular injury ${ }^{(5,7)}$. Therefore, the STZ-diabetic rat model may be suitable for investigating the antioxidant properties of hypoglycaemic agents ${ }^{(5,7)}$. GSH is the first line of defence against lipid peroxidation ${ }^{(8)}$. It is an essential electron donor to glutathione peroxidases in reducing hydroperoxides and serves as a nucleophilic co-substrate to glutathione $S$-transferases in detoxifying xenobiotics $^{(8)}$.

Many spices show hypoglycaemic and antioxidant ᄃ activities and are less toxic than Western medicines ${ }^{(9-11)}$. Garlic (Allium sativum, family Alliaceae), ginger (Zingiber officinale, family Zingiberaceae) and turmeric (Curcuma longa, family Zingiberaceae) have been widely used as dietary spices and for the treatment of various ailments in folk medicine since ancient times ${ }^{(9-11)}$. Asian people typically consume $2-4 \mathrm{~g} / \mathrm{d}$ of these spices in culinary use. Garlic bulb (rich in alliin, a precursor of allicin, $1-2.5 \%$ ), turmeric rhizome (rich in phenolic curcuminoids, 3-5\%) and ginger rhizome (rich in pungent phenolic compounds, gingerols and shogaols, $1-3 \%$ ) in the form of dried powders or their extracts are important ingredients of many traditional and alternative medicines worldwide ${ }^{(12-14)}$. The present study compared the modulatory effects of pure dried powder of garlic bulb as well as ginger and turmeric rhizomes separately and mixed together (for the first time to our knowledge) on hyperglycaemia, dyslipidaemia and impaired antioxidant defence system (especially GSH) in STZ-nicotinamide diabetic rats. Moreover, the present study examined any deleterious effects caused by feeding healthy rats these spices. Because these plants are used as dietary spices and supplements, their antidiabetic effects were investigated in the present study via oral administration.

\section{Materials and methods}

\section{Chemicals}

STZ $\left(\mathrm{C}_{8} \mathrm{H}_{15} \mathrm{~N}_{3} \mathrm{O}_{7} ;\right.$ molecular weight $\left.265 \cdot 22 \mathrm{Da}\right)$ and nicotinamide $\left(\mathrm{C}_{6} \mathrm{H}_{6} \mathrm{~N}_{2} \mathrm{O} ;\right.$ molecular weight $\left.122 \cdot 12 \mathrm{Da}\right)$ were purchased from Sigma-Aldrich (St Louis, MO, USA). Pure $(100 \%)$ dried powder of garlic bulb as well as ginger and turmeric rhizomes (AL-AMEER Brand) was authenticated and purchased from a herbal-specialised company (Kazerooni Brothers Establishment Company, Manama, Bahrain).

\section{Animals}

Adult male Wistar albino rats (Rattus norvegicus), weighing about 120-130g, were obtained from the College of Veterinary Medicine and Animal Resources, King Faisal University, Al-Hufof, KSA. Animals were housed in suitable cages and acclimatised to laboratory conditions for a period of 1 week before the commencement of the experiments. Rats were fed standard rodent food pellets (ARASCO, Riyadh, KSA) and distilled water. The standard rodent food pellets contain cereals, wheat bran, soya, molasses, alfalfa, minerals and vitamins. The amount of ash and crude proteins, fibres and fats in the food pellets are 80, 130, 100 and $20 \mathrm{~g} / \mathrm{kg}$, respectively. All animals were humanely treated in accordance with the WHO guidelines for animal care, and the study design was approved by the King Faisal University Research Ethics Committee.

\section{Induction of diabetes}

Diabetes was induced in overnight fasted rats by STZ (a single intraperitoneal injection of $65 \mathrm{mg} / \mathrm{kg}$ body weight) and nicotinamide (a single intraperitoneal injection of $110 \mathrm{mg} / \mathrm{kg}$ body weight, $15 \mathrm{~min}$ before STZ injection) as described previously ${ }^{(5)}$. STZ and nicotinamide were dissolved in citrate buffer ( $\mathrm{pH} 4.5)$ and physiological saline, respectively. Rats with blood glucose level more than $2000 \mathrm{mg} / \mathrm{l}$ ( $72 \mathrm{~h}$ after STZ injection) were used in the present study as diabetic rats.

\section{Experimental design and treatment schedule}

Animals were randomly divided into ten groups of six animals each: five healthy (non-diabetic) groups and five STZ-nicotinamide diabetic groups. Non-diabetic rats were intraperitoneally injected with saline and orally received (by gavage) either distilled water (healthy control group) or $200 \mathrm{mg} / \mathrm{kg}$ body weight of garlic bulb, ginger rhizome or turmeric rhizome powder suspension separately or mixed together (GGT mixture) for twenty-eight consecutive days. STZ-nicotinamide diabetic rats orally received either distilled water (diabetic control group) or $200 \mathrm{mg} / \mathrm{kg}$ body weight of garlic bulb, ginger rhizome or turmeric rhizome powder suspension separately or mixed together (GGT mixture) for twenty-eight consecutive days.

\section{Blood and tissue sampling}

Animals were fasted overnight and subjected to light diethyl ether anaesthesia before killing on day 29. Blood was collected into clean and dry test-tubes without EDTA to separate serum, which was divided into aliquots and preserved at $-40^{\circ} \mathrm{C}$ until used for biochemical analysis. The liver was quickly perfused in situ (via the hepatic portal vein) with a PBS solution to remove erythrocytes 
and clots, and then homogenised in cold PBS solution containing $1 \mathrm{mm-EDTA}$ ( $\mathrm{pH} 7 \cdot 4$ ) after the gall bladder was dissected away. The homogenate was collected, and its protein content was assayed by the method of Lowry et al. ${ }^{(15)}$. Thereafter, it was divided into aliquots and stored at $-40^{\circ} \mathrm{C}$ until used for the determination of tissue thiobarbituric acid-reactive substances (TBARS, for monitoring lipid peroxidation) and GSH.

\section{Measurements}

Food intake (on a per-group basis) was measured weekly. Body-weight change was assessed. Serum glucose concentration was estimated using glucose oxidase and peroxidase $^{(16)}$. Quantitative measurement of serum insulin concentration was performed using an insulin (rat) EIA kit (Alpco Diagnostics, Salem, NH, USA) according to the manufacturer's recommendations. Serum total lipid concentration was chemically determined by the phosphovanillin method $^{(17)}$. Serum TAG ${ }^{(18)}$, total cholesterol ${ }^{(19)}$ and HDL-cholesterol $^{(20)}$ concentrations were colorimetrically determined using peroxidase-coupled methods. Serum LDL-cholesterol concentration was calculated according to the equation of Friedewald et $a l^{(21)}$ :

$$
\begin{aligned}
\text { LDL-cholesterol }= & \text { total cholesterol }-(\mathrm{TAG} / 5) \\
& -(\text { HDL-cholesterol }) .
\end{aligned}
$$

Atherogenic indices were calculated as follows:

$$
\begin{aligned}
& \text { Atherogenic index }(1)= \text { total cholesterol/ } \\
& \text { HDL-cholesterol ratio, } \\
& \text { Atherogenic index }(2)=\text { LDL-cholesterol/ }
\end{aligned}
$$$$
\text { HDL-cholesterol ratio. }
$$

(a)

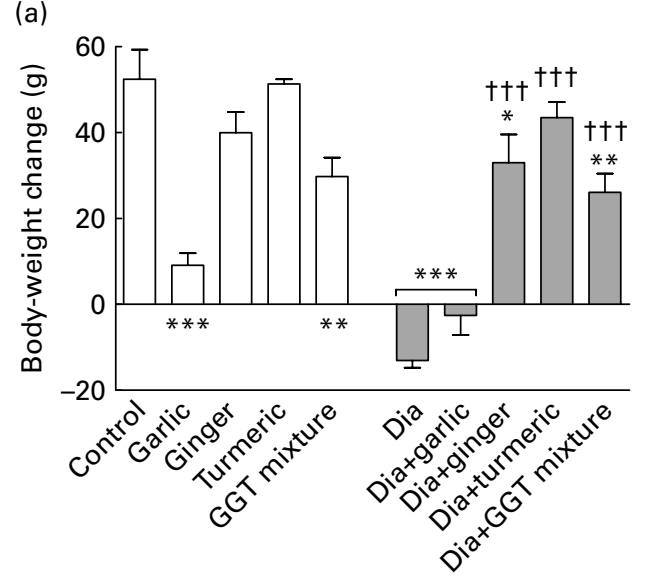

Serum alanine aminotransferase (ALAT) and aspartate aminotransferase activities were colorimetrically measured $^{(22)}$. Serum alkaline phosphatase activity was estimated from the rate of conversion of $p$-nitrophenylphosphate to $p$-nitrophenol ${ }^{(23)}$. Serum total antioxidants and liver TBARS concentrations were determined by the methods of Miller et al. ${ }^{(24)}$ and Ohkawa et $a l .{ }^{(25)}$, respectively. Liver GSH concentration was determined from the reaction of the sulfhydryl group with Ellman's reagent to give 5-thio-2-nitrobenzoic $\operatorname{acid}^{(26)}$. The percentage of difference of any parameter $=((T-C) / C) \times 100$, where $T$ is the mean value of the parameter in the treated group and $C$ is the mean value of the parameter in the healthy control group.

\section{Statistics}

Data are presented as means with their standard errors. Statistical analysis was performed with one-way ANOVA, and the differences among groups were determined by Bonferroni's multiple comparison test ${ }^{(27)}$ using GraphPad Prism version 4.03 for Windows (GraphPad Software, Inc., San Diego, CA, USA). $P$ values of $<0.05,<0.01$ and $<0.001$ were considered statistically significant, highly significant and very highly significant, respectively.

\section{Results}

Effects of garlic, ginger, turmeric and their mixture on body-weight gain and food intake in healthy and diabetic rats

The present study showed that neither ginger nor turmeric significantly affected body-weight gain in non-diabetic rats $(P>0.05)$, but both garlic and the GGT mixture significantly decreased weight gain by $83 \%(P<0.001)$ and $43 \%(P<0 \cdot 01)$, respectively (Fig. 1(a)). Diabetic rats that received vehicle showed a significant decrease in

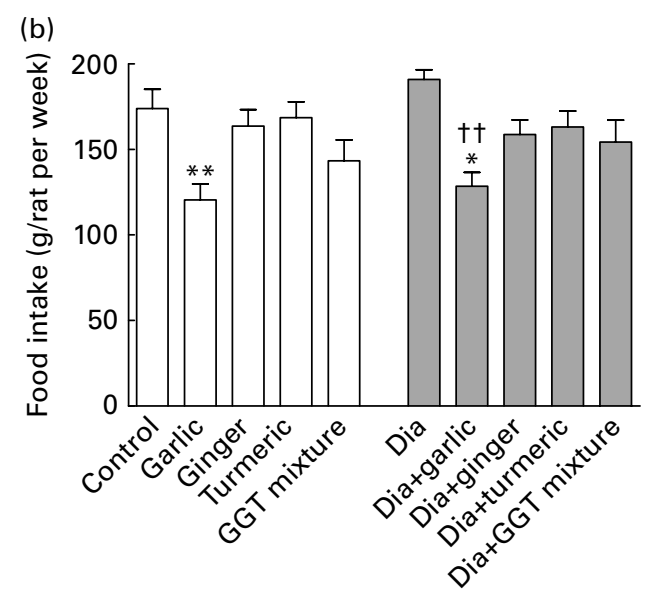

Fig. 1. Body-weight change (a) and food intake (b) in control ( $\square$ ) and diabetic ( $\square$ ) rats (Dia) given vehicle or vehicle plus garlic, ginger, turmeric or their mixture for $28 \mathrm{~d}$. GGT mixture, mixture of garlic, ginger and turmeric. Values are means, with their standard errors represented by vertical bars. Mean values were significantly different from that of the control group: ${ }^{\star} P<0.05$, ${ }^{\star \star} P<0.01$, ${ }^{\star \star *} P<0.001$. Mean values were significantly different from that of the diabetic group that received vehicle only: $\dagger+P<0.01$, $\dagger \dagger+P<0.001$. 
body-weight gain $(125 \%$ less, $P<0 \cdot 001, \quad t=10 \cdot 42$, difference between means 65.53, 95\% CI 46.46, 84.60, compared with healthy rats that received vehicle). This loss was completely prevented by turmeric $(P>0.05$ and $P<0.001$ compared with healthy and diabetic rats that received vehicle, respectively, Fig. 1(a)). On the other hand, food intake was significantly decreased by garlic in healthy and diabetic rats (26-31\% less, $P<0 \cdot 05-0 \cdot 01$, Fig. 1(b)).

Effects of garlic, ginger, turmeric and their mixture on serum glucose and insulin levels in healthy and diabetic rats

Garlic, ginger, turmeric or the GGT mixture did not significantly alter $(P>0.05)$ the serum glucose (Fig. 2(a)) and insulin (Fig. 2(b)) levels in healthy rats. On the other hand, diabetic rats that received vehicle showed hyperglycaemia (203\% more, $P<0.001, t=17.55$, difference between means - 1672, 95\% CI - 1961, - 1383) and hypoinsulinaemia (35\% less, $P<0 \cdot 01, t=4.094$, difference between means 0.339 , 95\% CI 0.088, 0.589). These effects were completely prevented by garlic, turmeric or the GGT mixture ( $P>0.05$; Fig. 2). Although ginger prevented hypoinsulinaemia in diabetic rats (Fig. 2(b)), its modulation on hyperglycaemia was partial, but significant $(P<0.05$ and $P<0.001$ compared with healthy and diabetic rats that received vehicle, respectively, Fig. 2(a)).

Effects of garlic, ginger, turmeric and their mixture on serum lipid profile and atherogenic indices in healthy and diabetic rats

Serum lipid profile (Table 1) and atherogenic indices (Fig. 3) did not significantly differ in healthy rats treated with garlic, ginger, turmeric or the GGT mixture
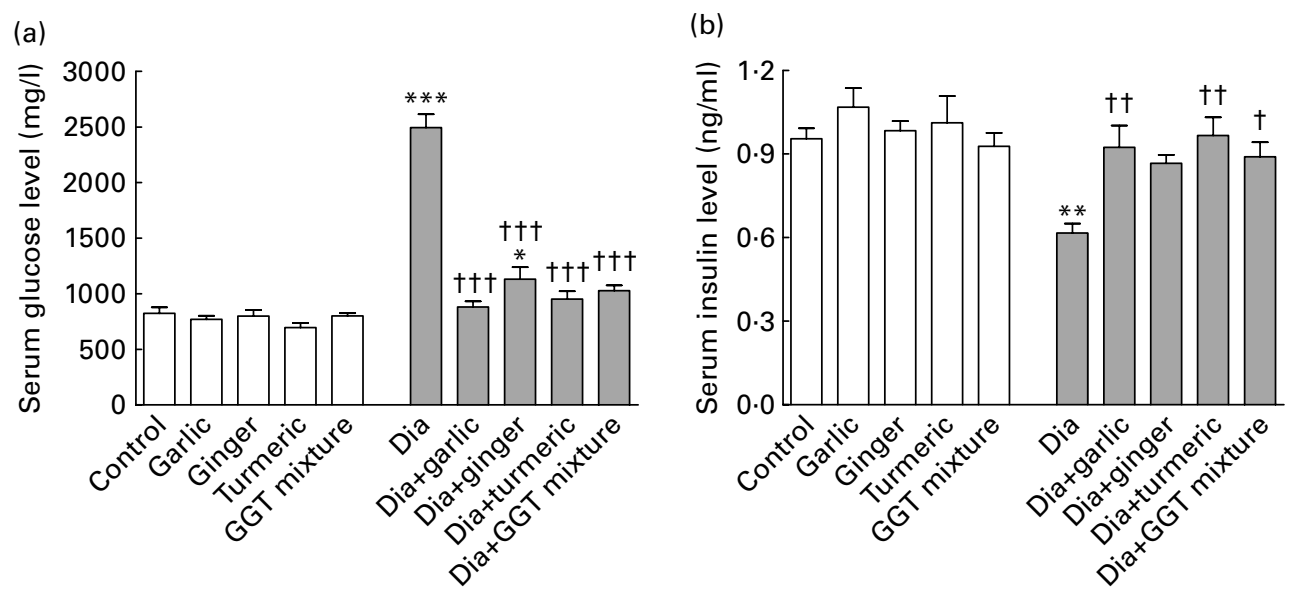

Fig. 2. Levels of serum glucose (a) and insulin (b) in control ( $\square$ ) and diabetic ( $\square$ ) rats (Dia) given vehicle or vehicle plus garlic, ginger, turmeric or their mixture for $28 \mathrm{~d}$. GGT mixture, mixture of garlic, ginger and turmeric. Values are means, with their standard errors represented by vertical bars. Mean values were significantly different from that of the control group: ${ }^{\star} P<0.05$, ${ }^{\star \star} P<0.01$, ${ }^{\star \star \star} P<0.001$. Mean values were significantly different from that of the diabetic group that received vehicle only: $\uparrow P<0.05$, †† $P<0.01$, $† \dagger \dagger P<0.001$.
$(P>0.05)$, except that the total lipids and total cholesterol significantly decreased by $37-47 \%(P<0.05-0.01)$ in those treated with the GGT mixture, compared with healthy rats that received vehicle. On the other hand, diabetic rats that received vehicle showed a significant decrease in the HDL-cholesterol level ( $42 \%$ less, $P<0 \cdot 05, t=3 \cdot 061$, difference between means $10 \cdot 14,95 \%$ CI $0 \cdot 10,20 \cdot 18)$ and a significant increase $(P<0.05-0.001)$ in total lipids, TAG, total cholesterol and LDL-cholesterol levels (31-333\% more; Table 1) as well as atherogenic indices (286-766\% more; Fig. 3) compared with healthy rats that received vehicle. All of these changes in serum lipids and atherogenic indices turmeric or the GGT mixture (Table 1 and Fig. 3), except that the modulation on hypertriacylglycerolaemia was partial, but significant, in diabetic rats that received ginger $(P<0.05$ and $P<0.001$ compared with healthy and diabetic rats that received vehicle, respectively, Table 1 ).

\section{Effects of garlic, ginger, turmeric and their mixture on cellular toxicity markers and antioxidants in healthy and diabetic rats}

Garlic, ginger, turmeric or the GGT mixture did not significantly change $(P>0.05)$ the cellular toxicity markers (serum ALAT, aspartate aminotransferase and alkaline phosphatase activities as well as liver TBARS level) in addition to serum total antioxidants and liver GSH levels in healthy rats (Table 2). On the other hand, diabetic rats that received vehicle showed a significant increase in cellular toxicity markers (29-207\% more, $P<0.05-0.001)$ and a significant decrease in serum total antioxidant level $(30 \%$ less, $P<0.01, t=3.855$, difference between means 0.095 , $95 \%$ CI $0 \cdot 02,0 \cdot 17)$ as well as liver GSH level (49\% less, $P<0.05, t=3 \cdot 433$, difference between means $1 \cdot 646,95 \%$ CI $0 \cdot 19,3 \cdot 10)$ compared with healthy rats that received of diabetic rats were completely prevented by garlic, ginger, (b) 
Table 1. Levels of lipids in control and diabetic rats (Dia) given vehicle or vehicle plus garlic, ginger, turmeric or their mixture for $28 \mathrm{~d}$ (Mean values with their standard errors)

\begin{tabular}{|c|c|c|c|c|c|c|c|c|c|c|}
\hline & \multicolumn{2}{|c|}{ Total lipids (mg/l) } & \multicolumn{2}{|c|}{ TAG (mg/l) } & \multicolumn{2}{|c|}{$\begin{array}{c}\text { Total cholesterol } \\
(\mathrm{mg} / \mathrm{l})\end{array}$} & \multicolumn{2}{|c|}{$\begin{array}{l}\text { HDL-choles- } \\
\text { terol (mg/l) }\end{array}$} & \multicolumn{2}{|c|}{$\begin{array}{l}\text { LDL-cholesterol } \\
\text { (mg/l) }\end{array}$} \\
\hline & Mean & SEM & Mean & SEM & Mean & SEM & Mean & SEM & Mean & SEM \\
\hline Control & 3304 & 291 & 716 & 84 & 524 & 36 & 246 & 24 & 135 & 30 \\
\hline Garlic & 2694 & 101 & 506 & 34 & 330 & 24 & 181 & 19 & 47 & 6 \\
\hline Ginger & 2703 & 184 & 561 & 48 & 392 & 24 & 206 & 19 & 75 & 23 \\
\hline Turmeric & 2642 & 186 & 495 & 45 & 417 & 47 & 225 & 23 & 94 & 26 \\
\hline GGT mixture & $2095^{\star \star}$ & 159 & 440 & 48 & $276^{*}$ & 32 & 167 & 22 & 21 & 4 \\
\hline Dia & $4327^{\star}$ & 242 & $1719^{\star \star \star \star}$ & 103 & $1072^{\star \star \star}$ & 80 & $144^{*}$ & 27 & $584^{\star * *}$ & 65 \\
\hline Dia + garlic & $2958+† \dagger$ & 251 & $890+\dagger \dagger$ & 99 & $527+\dagger \dagger$ & 49 & 163 & 16 & $187+† \dagger$ & 29 \\
\hline Dia + ginger & $3336 \dagger$ & 219 & $1067^{*}+\dagger \dagger$ & 89 & $617 \dagger+\dagger$ & 68 & 179 & 21 & $225+\dagger \dagger$ & 43 \\
\hline Dia + turmeric & $3076+\dagger$ & 263 & $817 \dagger+\dagger$ & 76 & $603+† \dagger$ & 66 & 205 & 25 & $234 † \dagger \dagger$ & 46 \\
\hline Dia + GGT mixture & 2736††† & 90 & $786+\dagger \dagger$ & 127 & 546††† & 85 & 204 & 32 & $184 \dagger \dagger \dagger$ & 58 \\
\hline
\end{tabular}

GGT mixture, mixture of garlic, ginger and turmeric.

Mean values were significantly different from that of the control group: ${ }^{\star} P<0.05,{ }^{\star \star} P<0.01,{ }^{\star \star \star} P<0.001$.

Mean values were significantly different from that of the diabetic group that received vehicle only: $\dagger P<0.05, \dagger \dagger P<0.01, \dagger \dagger \dagger P<0.001$.

vehicle (Table 2). All of these harmful changes were prevented by garlic and the GGT mixture $(P>0.05$ compared with healthy rats that received vehicle). Also, turmeric completely prevented all of the aforementioned changes in diabetic rats, except that the increase in serum ALAT activity was partially modulated $(P<0 \cdot 01$, $t=4 \cdot 08$, difference between means $-17 \cdot 26$, 95\% CI $-30.08,-4.43$, compared with healthy rats that received vehicle). In addition, the increase in serum alkaline phosphatase activity and the decrease in serum total antioxidants and liver GSH levels were completely modulated $(P>0 \cdot 05)$, but the increase in serum ALAT and aspartate aminotransferase activities as well as liver TBARS level was partially modulated $(P<0.05-0.01)$, in diabetic rats that received ginger compared with healthy rats that received vehicle (Table 2).

\section{Discussion}

The present study showed that garlic, ginger, turmeric and their mixture significantly alleviated (80-97\%,
$P<0.05-0.001)$ most signs of the metabolic syndrome including hyperglycaemia and dyslipidaemia, the elevation in atherogenic indices, and cellular toxicity in STZ-nicotinamide diabetic rats by increasing the production of insulin (26-37\%), reactivating the antioxidant defence system (31-52\%, especially GSH) and decreasing lipid peroxidation (60-97\%). The greatest effect was observed in diabetic rats that received the GGT mixture and garlic (10-23\% more than that in ginger and turmeric). The hypolipidaemic effect and the marked decrease in atherogenic indices shown in the present study in diabetic rats that received the aforementioned spices (Table 1 and Fig. 3) suggest that they might lower the risk of atherosclerosis. The decrease in serum ALAT, aspartate aminotransferase and alkaline phosphatase activities as well as liver TBARS level and the increase in the liver GSH level induced in diabetic rats by garlic, ginger, turmeric and the GGT mixture (Table 2) suggest that the chemical components of these spices prevented hepatocellular damage by stabilising the integrity of the cell
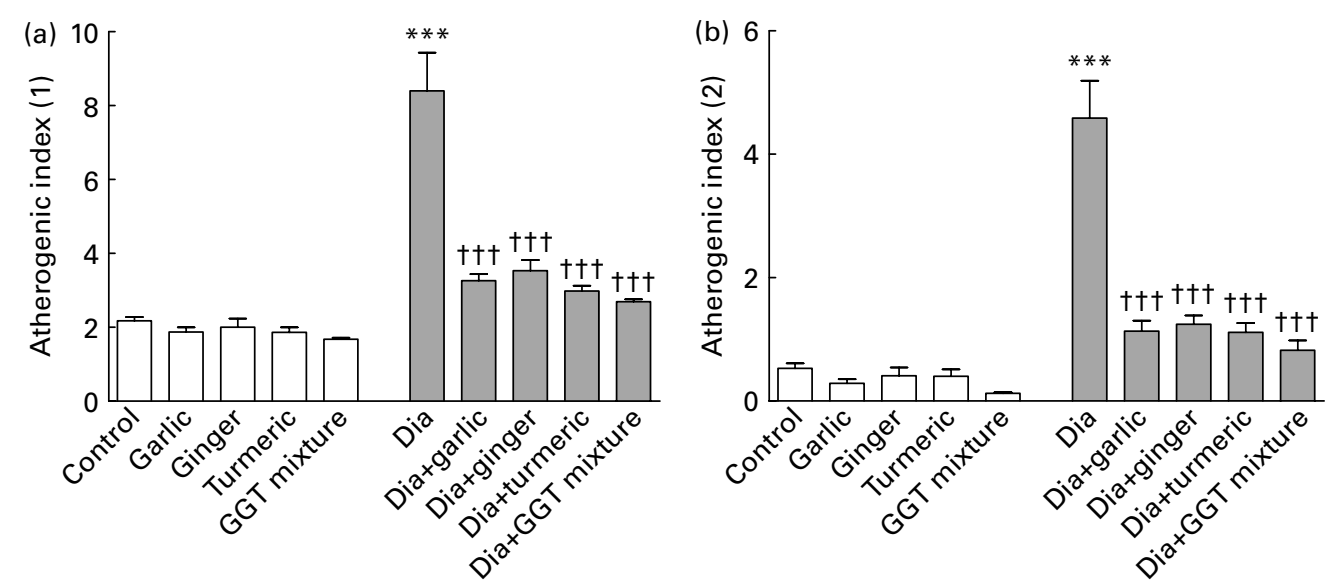

Fig. 3. Atherogenic indices in control $(\square)$ and diabetic $(\square)$ rats (Dia) given vehicle or vehicle plus garlic, ginger, turmeric or their mixture for 28 d. Atherogenic index (1), total cholesterol:HDL-cholesterol ratio; atherogenic index (2), LDL-cholesterol:HDL-cholesterol ratio; GGT mixture, mixture of garlic, ginger and turmeric. Values are means, with their standard errors represented by vertical bars. Mean values were significantly different from that of the control group: ${ }^{\star \star \star} P<0 \cdot 001$. Mean values were significantly different from that of the diabetic group that received vehicle only: $\uparrow \dagger \uparrow P<0 \cdot 001$. 
Table 2. Levels of cellular toxicity markers and antioxidants in control and diabetic rats (Dia) given vehicle or vehicle plus garlic, ginger, turmeric or their mixture for $28 \mathrm{~d}$

(Mean values with their standard errors)

\begin{tabular}{|c|c|c|c|c|c|c|c|c|c|c|c|c|}
\hline & \multicolumn{8}{|c|}{ Serum } & \multicolumn{4}{|c|}{ Liver } \\
\hline & \multicolumn{2}{|c|}{$\begin{array}{l}\text { ALAT activity } \\
\text { (IU/I) }\end{array}$} & \multicolumn{2}{|c|}{$\begin{array}{l}\text { ASAT activity } \\
\text { (IU/I) }\end{array}$} & \multicolumn{2}{|c|}{$\begin{array}{l}\text { ALP activity } \\
\text { (IU/I) }\end{array}$} & \multicolumn{2}{|c|}{$\begin{array}{l}\text { Total antioxidant } \\
\text { level }(\mathrm{mmol} / \mathrm{ml})\end{array}$} & \multicolumn{2}{|c|}{$\begin{array}{l}\text { TBARS level } \\
\text { ( } \mu \mathrm{M} / \mathrm{mg} \text { protein) }\end{array}$} & \multicolumn{2}{|c|}{$\begin{array}{c}\text { GSH level } \\
(\mu \mathrm{M} / \mathrm{mg} \text { protein })\end{array}$} \\
\hline & Mean & SEM & Mean & SEM & Mean & SEM & Mean & SEM & Mean & SEM & Mean & SEM \\
\hline Control & 43.0 & $1 \cdot 2$ & 88.9 & $1 \cdot 8$ & 54.5 & $2 \cdot 1$ & 0.318 & 0.024 & 0.273 & 0.032 & $3 \cdot 38$ & 0.23 \\
\hline Garlic & 40.5 & 1.3 & 81.5 & 4.4 & $49 \cdot 2$ & $2 \cdot 2$ & 0.367 & 0.030 & 0.244 & 0.033 & $3 \cdot 22$ & 0.31 \\
\hline Ginger & $46 \cdot 4$ & $1 \cdot 2$ & $86 \cdot 3$ & $2 \cdot 4$ & $50 \cdot 4$ & 3.4 & 0.387 & 0.006 & 0.257 & 0.014 & $3 \cdot 14$ & 0.32 \\
\hline Turmeric & $40 \cdot 2$ & $1 \cdot 2$ & $86 \cdot 2$ & $2 \cdot 6$ & 48.6 & 2.9 & 0.377 & 0.021 & 0.254 & 0.035 & 2.98 & 0.42 \\
\hline GGT mixture & $37 \cdot 1$ & $1 \cdot 1$ & $76 \cdot 1$ & $2 \cdot 0$ & $46 \cdot 7$ & $3 \cdot 0$ & 0.390 & 0.008 & 0.277 & 0.038 & $3 \cdot 29$ & 0.49 \\
\hline Dia & $77 \cdot 3^{\star \star \star}$ & $2 \cdot 0$ & $151 \cdot 7^{\star \star \star}$ & $6 \cdot 8$ & $70 \cdot 2^{*}$ & $2 \cdot 1$ & $0.223^{* *}$ & 0.012 & $0.837^{\star \star *}$ & 0.051 & $1 \cdot 74^{*}$ & 0.12 \\
\hline Dia + garlic & $51 \cdot 3+1 \dagger$ & 1.4 & 96.4††† & $3 \cdot 8$ & $50 \cdot 0+\dagger$ & $2 \cdot 5$ & $0.352+\uparrow \dagger$ & 0.010 & $0.291+\dagger \dagger$ & 0.031 & 2.48 & 0.40 \\
\hline Dia + ginger & $60 \cdot 5^{\star \star}+\dagger$ & $6 \cdot 4$ & $123 \cdot 4^{\star \star} \dagger$ & $12 \cdot 4$ & $56 \cdot 6$ & $5 \cdot 2$ & $0.341 \dagger \dagger \dagger$ & 0.022 & $0.500^{*}+\dagger \dagger$ & 0.076 & 3.33† & 0.23 \\
\hline Dia + turmeric & $60 \cdot 3^{\star *}+\dagger$ & $5 \cdot 8$ & 103.5††† & 6.9 & $57 \cdot 4$ & $6 \cdot 2$ & $0.382 \dagger \dagger \dagger$ & 0.009 & $0.333+\uparrow \dagger$ & 0.028 & $2 \cdot 86$ & 0.46 \\
\hline $\begin{array}{l}\text { Dia + GGT } \\
\text { mixture }\end{array}$ & $47.5+t \dagger$ & $1 \cdot 3$ & $86.5+† \dagger$ & $5 \cdot 3$ & $48.9+\dagger$ & $3 \cdot 8$ & $0.374 \dagger \dagger \dagger$ & 0.013 & $0.458+\dagger \dagger$ & 0.090 & $3 \cdot 62 † \dagger$ & 0.22 \\
\hline
\end{tabular}

ALAT, alanine aminotransferase; ASAT, aspartate aminotransferase; ALP, alkaline phosphatase; TBARS, thiobarbituric acid-reactive substances; GGT mixture, mixture of garlic, ginger and turmeric.

Mean values were significantly different from that of the control group: ${ }^{\star} P<0.05,{ }^{\star \star} P<0.01,{ }^{\star \star \star} P<0.001$.

Mean values were significantly different from that of the diabetic group that received vehicle only: $\dagger P<0.05, \dagger \dagger P<0.01, \dagger \dagger \dagger P<0.001$.

membrane, keeping the membrane intact and the enzymes enclosed, through scavenging free radicals. The significant increase in body-weight gain $(P<0 \cdot 001)$, despite similar food consumption $(P>0.05)$, shown in diabetic rats that received ginger, turmeric or the GGT mixture compared with diabetic control rats that received vehicle suggested that these spices may have a positive anabolic effect through improving glucose metabolism. This effect may decrease the degeneration of the adipocytes and muscle tissues in diabetic patients, which occur to compensate for the energy lost from the body due to frequent urination and overconversion of glycogen to glucose.

Several studies have reported that garlic has hypoglycaemic and antioxidant effects ${ }^{(7,28)}$. Others have reported that consumption of a diet containing 5\% garlic powder significantly decreased serum glucose and total cholesterol in type 2 diabetic $\mathrm{db} / \mathrm{db}$ mice ${ }^{(29)}$. Commercially available garlic preparations in the form of oil, powder and pills are widely used for certain therapeutic purposes to lower blood sugar and to improve lipid profile. The hypoglycaemic potency of garlic has been attributed to allicinderived organosulphur compounds, which protect insulin from $-\mathrm{SH}$ inactivation by reacting with endogenous thiolcontaining molecules such as cysteine, glutathione and serum albumin ${ }^{(9)}$. Garlic significantly decreased the blood glucose level in glucose-loaded diabetic rats, which may be due to the inhibition of glucose absorption from the intestine and/or the enhancement of glucose utilisation by restoring the impaired insulin response through increasing the pancreatic secretion of insulin from existing $\beta$-cells ${ }^{(9,29)}$. Moreover, the antidiabetic effect of garlic was more effective than that of glibenclamide, a sulfonylurea drug that is used clinically to lower serum glucose by stimulating $\beta$-cells to release insulin and by promoting peripheral tissue uptake as well as utilisation of glucose ${ }^{(9)}$. The hypolipidaemic effect (TAG- and cholesterol-lowering properties) of garlic was probably due to the inhibition of enzymes involved in fatty acid and cholesterol synthesis ${ }^{(9)}$. On the other hand, lipid peroxidation (TBARS and malondialdehyde levels) was significantly reduced in diabetic rats that received garlic. This antioxidant activity of garlic has also been attributed to the presence of organosulphur compounds that increase glutathione content and the activity of antioxidant enzymes, such as superoxide dismutase as well as glutathione $S$-transferases ${ }^{(7,28)}$.

The hypoglycaemic and hypolipidaemic effects of ginger and its extracts has been reported previously in diabetic rats and mice ${ }^{(10,30-31)}$. Additionally, ginger was effective in reversing the diabetic proteinuria and body-weight loss observed in diabetic rats ${ }^{(10)}$. Ginger ethanolic extract has shown insulinotropic action similar to chlorpropamide, a sulphonylurea drug, and enhanced insulin sensitivity at the cellular level ${ }^{(31)}$. Also, ethanolic ginger extract reduced plasma cholesterol and inhibited LDL oxidation in atherosclerotic apoE-deficient mice ${ }^{(32)}$. Moreover, addition of ginger $(1 \%)$ to a normal diet prevented the formation of free radicals and maintained the integrity of rat erythrocytes $^{(33)}$. The antioxidant potency of ginger has been attributed to gingerols that prevent reactive oxygen species production $^{(14)}$. Aldose reductase inhibitors, which reduce sorbitol formation as well as its accumulation in human tissues such as erythrocytes and protect cells from osmotic damage, are now considered to have remarkable potential for the treatment of diabetes mellitus and its complications. At least two active components, 2-(4hydroxy-3-methoxyphenyl) ethanol and 2-(4-hydroxy-3methoxyphenyl) ethanoic acid, of ginger have shown aldose reductase inhibitor properties ${ }^{(14)}$. Also, ginger 
inhibited serotonin-induced hyperglycaemia and hypoinsulinaemia by blocking its receptors ${ }^{(10)}$.

Curcumin, one of the major phenolic curcuminoids of turmeric, has been shown to reduce hyperglycaemia and hyperlipidaemia in type 2 diabetic KK-Ay mice as well as STZ-diabetic and alloxan-diabetic rat models ${ }^{(5,12)}$. Also, it prevents the oxidation of $\mathrm{LDL}^{(12)}$. Tetrahydrocurcumin (one of the major metabolites of curcumin) exhibited antidiabetic and antioxidant properties in STZ-nicotinamide diabetic rats ${ }^{(5)}$. Curcumin and tetrahydrocurcumin protected pancreatic $\beta$-cells from reactive oxygen species generated in diabetes by scavenging free radicals and reactivating the antioxidant defence system ${ }^{(34)}$. They significantly increased the tissue GSH level in STZ-nicotinamide diabetic rats, which in turn activated the GSH-dependent antioxidant enzymes (such as glutathione peroxidases and glutathione $S$-transferases) and detoxified the highly reactive intermediates of $S T Z^{(5)}$. However, the antioxidant activity of tetrahydrocurcumin is more potent than that of curcumin ${ }^{(35)}$. Feeding STZ-diabetic rats with turmeric decreased the TBARS level and increased the activities of antioxidant enzymes such as superoxide dismutase, catalase, glutathione peroxidases and glutathione $S$-transferases in erythrocytes ${ }^{(11)}$. The present results are consistent with the aforementioned reports, which may explain the beneficial effects of garlic, ginger and turmeric as well as their mixture shown in the present study.

According to the data obtained in the present study, the modulatory effects of the GGT mixture were, in general, equal to that of garlic and more than that of turmeric and ginger. On the other hand, the modulatory effect of garlic on severe body-weight loss shown in diabetic rats was weak in the present study (Fig. 1(a)), which may be, in part, due to an effect of garlic on appetite, since it significantly decreased food intake in non-diabetic rats $(P<0.01$; Fig. 1(b)). Addition of ginger and turmeric to garlic alleviated the decrease in food intake and bodyweight loss induced by garlic in non-diabetic rats and ameliorated its modulatory effect on the severe body-weight loss of diabetic rats. No other harmful effects were detected for garlic, ginger, turmeric and the GGT mixture on any parameters measured in the present study. Moreover, the GGT mixture decreased significantly serum total lipids and total cholesterol levels in healthy rats, which may be beneficial as a prophylaxis against hypercholesterolaemia. In conclusion, garlic or the mix including garlic appears to have an impact on each of the measures made here and, overall, is more effective than ginger or turmeric in alleviating the risks of the metabolic syndrome and cardiovascular complications in STZ-nicotinamide diabetic rats.

\section{Acknowledgements}

The present study was supported by the Deanship of Scientific Research, King Faisal University (10033 to H. R. M.). The authors thank Mr Tameen M. Al-Yahian, our laboratory technician, for animal care. S. W. M. and G. R. planned the study and designed the experiments. H. R. M. and S. W. M., with assistance from G. R., carried out all experiments. G. R. performed the statistical analysis and summarised the results, and drafted the manuscript with assistance from S. W. M. and H. R. M. The authors have no potential financial conflict of interest.

\section{References}

1. Lefebvre P (2005) Diabetes yesterday, today and tomorrow. The action of the International Diabetes Federation. Rev Med Liege 60, 273-277.

2. Knuiman MW, Hung J, Divitini ML, et al. (2009) Utility of the metabolic syndrome and its components in the prediction of incident cardiovascular disease: a prospective cohort study. Eur J Cardiovasc Prev Rehabil 16, 235-241.

3. Chong PH \& Bachenheimer BS (2000) Current, new and future treatments in dyslipidaemia and atherosclerosis. Drugs 60, 55-93.

4. Merzouk H, Madani S, Chabane Sari D, et al. (2000) Time course of changes in serum glucose, insulin, lipids and tissue lipase activities in macrosomic offspring of rats with streptozotocin-induced diabetes. Clin Sci (Lond) 98, 21-30.

5. Murugan P \& Pari L (2007) Influence of tetrahydrocurcumin on erythrocyte membrane bound enzymes and antioxidant status in experimental type 2 diabetic rats. J Ethnopharmacol 113, 479-486.

6. Masiello P, Broca C, Gross R, et al. (1998) Experimental NIDDM: development of a new model in adult rats administered streptozotocin and nicotinamide. Diabetes $\mathbf{4 7}$, 224-229.

7. Anwar MM \& Meki AR (2003) Oxidative stress in streptozotocin-induced diabetic rats: effects of garlic oil and melatonin. Comp Biochem Physiol A Mol Integr Physiol 135, 539-547.

8. Barber DA \& Harris SR (1994) Oxygen free radicals and antioxidants: a review. Am Pharm NS34, 26-35.

9. Eidi A, Eidi M \& Esmaeili E (2006) Antidiabetic effect of garlic (Allium sativum L.) in normal and streptozotocin-induced diabetic rats. Phytomedicine 13, 624-629.

10. Al-Amin ZM, Thomson M, Al-Qattan KK, et al. (2006) Antidiabetic and hypolipidaemic properties of ginger (Zingiber officinale) in streptozotocin-induced diabetic rats. Br J Nutr 96, 660-666.

11. Suryanarayana $\mathrm{P}$, Satyanarayana A, Balakrishna $\mathrm{N}$, et al. (2007) Effect of turmeric and curcumin on oxidative stress and antioxidant enzymes in streptozotocin-induced diabetic rat. Med Sci Monit 13, BR286-BR292.

12. Shishodia S, Sethi G \& Aggarwal BB (2005) Curcumin: getting back to the roots. Ann N Y Acad Sci 1056, 206-217.

13. Amagase H (2006) Clarifying the real bioactive constituents of garlic. J Nutr 136, 716S-725S.

14. Ali BH, Blunden G, Tanira MO, et al. (2008) Some phytochemical, pharmacological and toxicological properties of ginger (Zingiber officinale Roscoe): a review of recent research. Food Chem Toxicol 46, 409-420.

15. Lowry OH, Rosebrough NJ, Farr AL, et al. (1951) Protein measurement with the Folin phenol reagent. $J$ Biol Chem 193, 265-275.

16. Trinder P (1969) Determination of glucose in blood using glucose oxidase with an alternative oxygen acceptor. Ann Clin Biochem 6, 24-27.

17. Knight JA, Anderson S \& Rawle JM (1972) Chemical basis of the sulfo-phospho-vanillin reaction for estimating total serum lipids. Clin Chem 18, 199-202. 
18. McGowan MW, Artiss JD, Strandbergh DR, et al. (1983) A peroxidase-coupled method for the colorimetric determination of serum triglycerides. Clin Chem 29, 538-542.

19. Allain CC, Poon LS, Chan CS, et al. (1974) Enzymatic determination of total serum cholesterol. Clin Chem 20, $470-475$.

20. Grove TH (1979) Effect of reagent $\mathrm{pH}$ on determination of high-density lipoprotein cholesterol by precipitation with sodium phosphotungstate-magnesium. Clin Chem $\mathbf{2 5}$, 560-564.

21. Friedewald WT, Levy RI \& Fredrickson DS (1972) Estimation of the concentration of low-density lipoprotein cholesterol in plasma, without use of the preparative ultracentrifuge. Clin Chem 18, 499-502.

22. Reitman S \& Frankel S (1957) A colorimetric method for the determination of serum glutamic oxalacetic and glutamic pyruvic transaminases. Am J Clin Pathol 28, 56-63.

23. Wenger C (1984) Alkaline phosphatase. In Clinical Chemistry, pp. 1094-1098 [A Kaplan, editor]. St Louis, MO: Mosby.

24. Miller NJ, Rice-Evans C \& Davies MJ (1993) A new method for measuring antioxidant activity. Biochem Soc Trans 21, 95S.

25. Ohkawa H, Ohishi N \& Yagi K (1979) Assay for lipid peroxides in animal tissues by thiobarbituric acid reaction. Anal Biochem 95, 351-358.

26. Ellman GL (1959) Tissue sulfhydryl groups. Arch Biochem Biophys 82, 70-77.

27. Turner JR \& Thayer JF (editors) (2001) Introduction to Analysis of Variance: Design, Analysis and Interpretation. Thousand Oaks, CA: Sage Publications.
28. Lee YM, Gweon OC, Seo YJ, et al. (2009) Antioxidant effect of garlic and aged black garlic in animal model of type 2 diabetes mellitus. Nutr Res Pract 3, 156-161.

29. Seo YJ, Gweon OC, Lee YM, et al. (2009) Effect of garlic and aged black garlic on hyperglycemia and dyslipidemia in animal model of type 2 diabetes mellitus. J Food Sci Nutr 14, 1-7.

30. Bhandari U, Kanojia R \& Pillai KK (2005) Effect of ethanolic extract of Zingiber officinale on dyslipidaemia in diabetic rats. J Ethnopharmacol 97, 227-230.

31. Ojewole JA (2006) Analgesic, antiinflammatory and hypoglycaemic effects of ethanol extract of Zingiber officinale (Roscoe) rhizomes (Zingiberaceae) in mice and rats. Phytother Res 20, 764-772.

32. Fuhrman B, Rosenblat M, Hayek T, et al. (2000) Ginger extract consumption reduces plasma cholesterol, inhibits LDL oxidation and attenuates development of atherosclerosis in atherosclerotic, apolipoprotein E-deficient mice. J Nutr 130, 1124-1131.

33. Ahmed RS, Seth V \& Banerjee BD (2000) Influence of dietary ginger (Zingiber officinale Rosc.) on antioxidant defense system in rat: comparison with ascorbic acid. Indian J Exp Biol 38, 604-606.

34. Srivivasan A, Menon VP, Periaswamy V, et al. (2003) Protection of pancreatic beta-cell by the potential antioxidant bis-o-hydroxycinnamoyl methane, analogue of natural curcuminoid in experimental diabetes. J Pharm Pharm Sci 6, 327-333.

35. Okada K, Wangpoengtrakul C, Tanaka T, et al. (2001) Curcumin and especially tetrahydrocurcumin ameliorate oxidative stress-induced renal injury in mice. J Nutr 131, 2090-2095. 